Illinois State University

ISU ReD: Research and eData

Theses and Dissertations

3-24-2021

\title{
Moral Modeling: How Heroes Impact Values
}

Christopher David Atkinson

Illinois State University, cody.atkinson98@gmail.com

Follow this and additional works at: https://ir.library.illinoisstate.edu/etd

Part of the Psychology Commons

\section{Recommended Citation}

Atkinson, Christopher David, "Moral Modeling: How Heroes Impact Values" (2021). Theses and Dissertations. 1350.

https://ir.library.illinoisstate.edu/etd/1350

This Thesis is brought to you for free and open access by ISU ReD: Research and eData. It has been accepted for inclusion in Theses and Dissertations by an authorized administrator of ISU ReD: Research and eData. For more information, please contact ISUReD@ilstu.edu. 


\section{MORAL MODELING: HOW HEROES IMPACT VALUES}

\section{CHRISTOPHER D. E. ATKINSON}

\section{Pages}

The Hero Functions Framework states that heroes play three functions in society: enhancing others, protecting those around them, and modeling morals for others (Kinsella et al., 2015b). This study evaluated the experimental validity of the moral modeling function of heroes. Experiencing heroes may lead a change in values to better align with the values of that heroes model. Moral elevation, the feeling of awe and inspiration one feels when witnessing a morally beautiful act (Aquino et al., 2011), may also mediate the relation between heroes and a change in one's values. Therefore, it was hypothesized that participants who reflected on heroes would report higher scores on measures of moral elevation and personal values than those who reflected on average college students. Two hundred and forty undergraduates reflected on either heroes or average college students and then completed measures of moral elevation and values. The results showed that reflecting on heroes had a significant effect on moral elevation but had no direct effect on any of the values, Wilks' $\Lambda=.92, F(5,234)=4.0, p=.002$. Mediation analyses showed that reflected on heroes had an indirect effect on benevolence through moral elevation ( $\beta$ $=.11,95 \% \mathrm{CI}=[.03, .19])$. These findings suggest that reflecting on heroes causes a higher prioritization of benevolence through moral elevation.

KEYWORDS: Heroes; Personal values; Moral elevation; Hero Function Framework 
MORAL MODELING: HOW HEROES IMPACT VALUES

CHRISTOPHER D. E. ATKINSON

A Thesis Submitted in Partial Fulfillment of the Requirements for the Degree of MASTER OF SCIENCE

Department of Psychology

ILLINOIS STATE UNIVERSITY

2021 
(C) 2021 Christopher D.E. Atkinson 
MORAL MODELING: HOW HEROES IMPACT VALUES

CHRISTOPHER D. E. ATKINSON

COMMITTEE MEMBERS:

Eric Wesselmann, Chair

Daniel Lannin 


\section{ACKNOWLEDGMENTS}

This project would not exist without the support and assistance from several individuals. I would like to my committee chair, Dr. Eric Wesselmann. Your guidance and input throughout this entire endeavor has made me a better researcher, scholar, and person. I would also like to thank my committee member Dr. Daniel Lannin whose expertise, advice, and encouragement helped me become a much better writer. Finally, I would like to thank Courtney Geske for her patience and many edits, I could not have done this without her support.

C.D.E.A 


\section{CONTENTS}

Page

ACKNOWLEDGMENTS

TABLES

FIGURES

$\begin{array}{ll}\text { CHAPTER I: INTRODUCTION } & 1\end{array}$

CHAPTER II: LITERATURE REVIEW

$\begin{array}{ll}\text { Defining Heroes } & 7\end{array}$

The Functions of Heroes $\quad 9$

Schwartz's Theory of Values $\quad 11$

$\begin{array}{ll}\text { Moral Elevation } & 13\end{array}$

$\begin{array}{ll}\text { The Current Study } & 14\end{array}$

$\begin{array}{ll}\text { Purpose } & 14\end{array}$

$\begin{array}{ll}\text { Hypotheses } & 16\end{array}$

$\begin{array}{ll}\text { Values } & 16\end{array}$

$\begin{array}{ll}\text { Moral Elevation } & 16\end{array}$

$\begin{array}{ll}\text { CHAPTER III: METHODS } & 17\end{array}$

$\begin{array}{ll}\text { Participants } & 17\end{array}$

$\begin{array}{ll}\text { Procedure } & 17\end{array}$

$\begin{array}{ll}\text { Hero Condition } & 17\end{array}$

$\begin{array}{ll}\text { College Student Condition } & 18\end{array}$

$\begin{array}{ll}\text { Dependent Measures } & 18\end{array}$

CHAPTER IV: RESULTS 20 
$\begin{array}{ll}\text { Hypothesis } 1 & 21\end{array}$

$\begin{array}{ll}\text { Hypothesis 2a } & 22\end{array}$

$\begin{array}{ll}\text { Hypothesis } 2 b & 23\end{array}$

$\begin{array}{ll}\text { Hypothesis 2c } & 23\end{array}$

Hypothesis 2d 23

CHAPTER V: DISCUSSION 25

Limitations and Future Research $\quad 27$

$\begin{array}{lr}\text { Conclusion } & 29\end{array}$

$\begin{array}{lr}\text { REFERENCES } & 30\end{array}$ 


\section{TABLES}

Table

Page

1. Means and Standard Deviations for Moral Elevation, Benevolence, Stimulation,

Achievement, and Tradition

2. Correlations for Moral Elevation, Benevolence Stimulation, Achievement, and

Tradition 


\section{FIGURES}

Figure $\quad$ Page

1. Standardized Regression coefficients for the relation between condition and benevolence as mediated by moral elevation. Hero condition was coded as one, control condition was coded zero 


\section{CHAPTER I: INTRODUCTION}

The research of heroes encompasses a variety of theories that attempt to describe heroic individuals and the impact heroes have on society. Early research discussed the social situations in which people would act heroically (Franco et al., 2011) and concluded that heroism is an action that should not be limited to one particular person or example. Other scholars disagreed with this finding and stated that personality also played a role in whether or not someone would choose to act heroically (Kohen et al., 2019). Others have taken a different approach to researching heroes by surveying public opinion on what qualities describe a hero. These studies concluded with a list of traits or characteristics that would lead an average person to think of a hero after reading it (Sullivan \& Venter, 2010; Allison \& Goethals, 2012; Kinsella et al., 2015a). Recent research has focused more on the utility of heroes and the roles they play that make them a necessity for society. Research on heroic narratives has shown that they fulfill needs for hope, wisdom, meaning, inspiration, and growth (Allison \& Goethals, 2016). Another study stated that heroes provide three main functions to society, enhancing others, protecting those around them, and modeling morals for other society members (Kinsella et al., 2015b). It is this lattermost line of research that provides a solid theoretical basis for the current study to evaluate heroes in a laboratory setting.

The Hero Functions Framework (HFF; Kinsella et al., 2015b) consists of the enhancing, protecting, and moral modeling. To determine this framework, researchers asked participants what functions they thought heroes performed and after four studies concluded that these various functions could be organized into three groups. The last of these groups, moral modeling, refers to the symbolic nature of heroes and how that can influence an individual's values and is the main focus of the present study. This function is similar to other research regarding moral 
exemplars, who are people that lead lives of moral excellence. In both cases heroes and moral exemplars are theorized to remind people of their values and demonstrate how to act morally in an immoral world. However, in order to evaluate to what extent moral modeling can influence an individual's values, it is important to discuss what values are.

One of the most widely accepted theory of values was introduced by Schwartz and originally had ten distinct values which was later expanded to 19 (Schwartz, 2017; Schwartz, 2012). These values are held by everyone to some degree. Theoretically, Schwartz's values create a quasi-circular structure with opposing values on opposite sides while similar values are located closer together. What makes one value different from another is the type of goal or motivations it represents. For example, someone valuing stimulation would be motivated to experience change or excitement while those who value tradition will be motivated to preserve cultural or familial traditions. Multiple studies conducted in several different countries have found that these values are universal in both structure and their relation to human motivation. The measurement of these values has been taken with several different instruments and has been shown to reflect a similar if not the same structure as the theoretical structure proposed by Schwartz. This theory of values has been shown to be valid in defining values as well as describing the relations between them. The general acceptance of this theory and its measures provide a valid way to connect values research to the seemingly unrelated field of hero research.

The purpose of the present study is to evaluate what extent one's values can be influenced by reflecting on heroic characteristics. This will be evaluated by having individuals reflect on heroic traits and apply these traits to someone in their life and asking them to complete a values measure. The results of this values measure will then be compared to a control condition to test if there is any difference between the two. The current study also aims to evaluate the 
moral modeling functions of heroes proposed by the HFF in a laboratory setting as well as attempting to test if feelings of moral elevation have any relation to the degree of influence heroes have on values. 


\section{CHAPTER II: LITERATURE REVIEW}

The science of heroism is a relatively new field in psychology (Allison \& Goethals, 2016) owing its creation to Phil Zimbardo a little over a decade ago (Franco et al., 2011). Since then, several researchers have investigated the nature of heroes, what situations they arise in, the perceived morality of their actions, the characteristics of heroes, and the functions they provide. Early research concerning heroes took a situationist approach and asserted that everyone had the potential to accomplish heroic deeds. The focus of this research was on listing what kind of actions could be considered heroic. These were split into a list of 3 categories of heroes that were subdivided into 12 groups depending on the type of risk. These categories are martial heroes, civil heroes, and social heroes. The first two categories included people taking immediate physical risks, with martial heroism being duty-bound (military personnel) and civil heroism being those who were not duty bound but still took the risk. For example, a civil hero is someone who jumps onto subway tracks to save another person. The latter category, social heroism, is meant to include those who choose to take a less immediate, non-physical risk (Franco et al., 2011). While social heroes do not face immediate physical danger, they are often faced with personal sacrifice, financial risk, social ostracism, and other long-lasting effects (Franco et al., 2011). This distinction was created to combat the notion that heroism is simply altruism with the addition of immediate risk (Becker \& Eagly, 2004).

It is important to note that this conceptualization of heroes concluded that heroism was a social act, not a personality trait. The authors argued that heroic acts were caused by certain situational factors and concluded that most individuals have the potential to act heroically. This conclusion was later named the banality of heroism (Franco et al. 2011). 
The situational perspective on heroism was not the only focus of these authors. Recent focus has been to foster the heroic imagination in order to guide others into heroic action (Kohen et al., 2019; Franco et al., 2011). Heroic imagination is comprised of three functions or components. The first of these functions pertains to how heroes are imagined in classic writings and by the general public. These notions of heroes are often vastly different from what heroes are like in reality, and extreme cases of this are theorized to discourage heroic acts due to them belittling a person's heroic potential. The next function discussed is the mindset of a hero and how they anticipate and remain ready for opportunities that require heroic action. This function implies that everyone has the potential to act heroically, thus lending itself to the banality of heroism. This anticipation function may also be related to prospection, or the process of mentally rehearsing hypothetical future situations (Kohen et al., 2019). This type of rehearsal may be what heroes do in order to react heroically. The third function or meaning of the phrase heroic imagination, conveys the bold reorganizations of society due to some social heroes. This function addresses how social heroes can impact entire societies with their words or actions (Franco et al., 2011). The heroic imagination is a morally optimistic version of hostile imagination, the desired goal of nation states that use propaganda in order to dehumanize and demonize those who would be considered an enemy. While hostile imagination captures the worst of humanity in either the affected party or the process by which the affected party is demonized, the heroic imagination embodies the best of humanity and how individuals can encapsulate heroic qualities. The heroic imagination was created and defined with application as being the main concern of the researchers. Most discussion of heroic imagination centers on developing interventions that foster it in order to assist others. This was an important first step in 
the field of the heroism because it attempted to describe how heroes affect society on an individual level.

Diverging from the situationist paradigm is the interactionist perspective, stating that there are individuals who could be considered to be moral exemplars, who show consistent behavior that is not entirely contingent on the situation. Moral exemplars people who others have determined to have led lives of moral excellence (Walker et al., 2010). This interactionalist perspective on heroism suggests that heroism is a product of situational factors interacting with personalities that consist of more salient moral values. Researchers had 50 participants who were national awardees for moral action and 50 average participants for comparison. The participants then completed multiple personality tests and researchers found that there were differences in personality characteristics between the groups which would suggest that high moral functioning can take many forms across many situations (Walker et al., 2010). Therefore, those who act heroically have personalities that predispose them to act heroically in certain situations.

This consistency on the personality aspect of heroic interactions contrasts with the situationist view of heroes that denies the existence of a heroic or moral disposition and instead focuses on the contextual factors present in a heroic act (Franco et al., 2011). Several academic disciplines have worked with psychologists in order to determine 5 criteria that individuals should meet in order to be considered moral exemplars: a commitment to moral ideals, a disposition to act according to those ideals, a willingness to risk one's self-interest for the sake of one's ideals, the tendency to inspire moral action in others, and a sense of humility (Matsuba \& Walker, 2005). While these criteria were created with moral exemplars in mind, it is not a stretch to say that heroes also possess these qualities and characteristics. Researchers also found while 
interviewing 23 nationally recognized moral exemplars that there were three similarities each statement had in common. These individuals possess a certainty about their beliefs, demonstrating that during difficult periods they continued to have a positive outlook, and the moral goals of exemplars were found to be united with their sense of self. Situationist and interactionist paradigms investigated the personality and situational factors that contribute to heroism and in doing so seem to represent both sides of a heroic act. Situationist authors discuss how the heroic imagination can change the situation so the heroic potential of key individuals can be achieved while interactionist authors discuss the qualities possessed by moral exemplars. Putting both schools of thought together, it can be concluded that heroes are moral exemplars who have fostered their own heroic imagination so that they are willing and able to do the right thing no matter the cost. One unaccounted factor, save the first component of heroic imagination, is the effect of fictional heroes and the stories they inhabit. This branch of research focuses on what characteristics make a hero, rather than what actions can be considered heroic.

\section{Defining Heroes}

Early research focused on creating criteria to determine whether someone or something could be considered heroic. This research focused on describing those who were already considered heroes in public opinion. The benefit of this new method of studying heroes is that it avoids the debates of morality inherent in using a real-world example. Instead of studying the specifics of any one hero, this research looks to describe the hero archetype. Two studies went about trying to define what traits make up a hero by using the participants own schemas of heroes. One of these studies surveyed asked 75 participants to list traits that they believed to characterize heroes, and after having 50 other participants sort the traits based on similarities or differences between them. They found that there were approximately eight clusters of related 
traits that researchers then called the 'Great Eight of heroism': caring, charisma, inspiring, reliable, resilient, selfless, smart, and strong (Allison \& Goethals, 2012). Other studies used similar methods of collecting and validating traits that characterize heroes. One such study found that qualities such as intelligent, loving, and religious were the top three characteristics used to characterize heroes (Sullivan \& Venter, 2010). This study also found that the notion of heroes can be based on specific qualities inherent in the hero and on the self-views of the person describing or identifying the hero (Sullivan \& Venter, 2010).

Another attempt to characterize heroes conducted seven studies using a similar process of sorting and grouping various qualities and then verifying them by comparing the relatedness of the traits and the participants' notions of heroes (Kinsella et al., 2015a). Results showed that, in comparison to similar archetypes such as leaders and role models, the character traits most related to heroes consist of: bravery, moral integrity, courageousness, protecting, conviction, honesty, altruism, self-sacrifice, selflessness, determination, saving, inspiring, and helpful (Kinsella et al., 2015a). The interesting distinction made in this line of research is the recognition that while the archetypes of heroes, leaders, and role models tend to have overlapping traits but are still different from one another.

This research expands on previous literature by noting that central and peripheral traits determine the degree of separation archetypes, such as between hero and role model. Central traits were defined as those that were communicated by participants more frequently while peripheral traits were not addressed as frequently. The purpose of this distinction was to address the fact that this overlap between heroes, leaders, and role models are similar due to similar peripheral traits. This contrasts previous literature which merged archetypes similar to heroes under the same umbrella (Allison \& Goethals, 2016; Sullivan \&Venter, 2010). These studies also 
concluded that the central traits could activate the schemas of either archetype (Kinsella et al., 2015a). This is an interesting development in the science of heroes due to the fact that the results this research proposes that a participant could be primed to think about heroes, leaders, or role models without having the inherent errors of using a particular example. This is a benefit because most of the previous literature has consisted of investigating real world instances of heroism. The results found by both of the previous studies serve as the first step to investigate the effects that heroes have on the average person. Heroes and their stories likely have some utility or purpose in society or why else would society keep them around? It was this thought that led researchers to investigate the roles or functions heroes have in society.

\section{The Functions of Heroes}

One approach attempting to describe the hero phenomena is to specify the functions of heroes. Research in this subfield focuses on what psychological needs heroes fulfill rather than trying to discern what actions or people can be considered heroic or what characteristics a hero has. The heroes discussed in this literature can be either real or fictional because the purpose of this research is not the hero itself but the individual being affected by the hero. Therefore, this research includes heroic narratives in how they study the effects of heroes. One such theory is a framework called the heroic leadership dynamic (HLD; Allison \& Goethals, 2016). This framework posits that heroes fulfill specific cognitive and emotional needs such as the need for wisdom, hope, inspiration, and growth (Allison \& Goethals, 2016). HLD also explains the initial attraction to heroes and later retention or rejection of heroes. This is because people often find themselves learning lessons while interacting with heroic narratives and being affected through several different cognitive and emotional processes. As people grow older, what is needed from 
these narratives change and can lead to either the rejection or retention of those stories and their lessons.

In the HLD framework, hero stories serve both epistemic and energizing functions. The epistemic function refers to the knowledge and wisdom being imparted into the consumers of these narratives. This understanding can be mental models or scripts about how one should act in certain situations or reveal truths about life which are often masked as symbols and metaphors (Allison \& Goethals, 2016). The energizing function refers to the moral elevation and the healing properties that these stories have on their readers or viewers. Moral elevation is described as the feeling of awe and admiration when observing a morally beautiful act (Allison \& Goethals, 2016; Aquino et al., 2011). This can be likened to when someone witnesses an aesthetically beautiful object or act. These stories also have healing properties and can aid others with psychological wounds in several different ways such as community building, promoting personal growth, and inspiring the reader. HLD suggests that the notion of heroes is introduced through stories rather than direct experience. This may be what first fosters the heroic imagination discussed earlier and explains the indirect effects heroes have on those who encounter them.

While HLD focuses mainly on heroic narratives, other researchers have looked to common conceptions about heroes in general to describe their functions. Researchers conducted four studies that investigated lay conceptions about the functions of heroes (Kinsella et al., 2015b). These studies found that common functions of heroes were enhancing, protecting, and moral modeling. The enhancing function of heroes is explained as how heroes motivate, inspire, instill hope, improve morale, and guide others (Kinsella et al., 2015b). This explains how heroes can lift others up and motivate them to be their best selves. This is similar to the energizing function (Allison \& Goethals, 2016) in that heroes tend to make those who witness their actions 
change their own behavior. The protecting function relates to the main function of heroes is to protect others, act against evil or danger, and do things that no one else will (Kinsella et al., 2015b). This function is fairly self-explanatory because protecting others is often a characteristic of someone that makes them hero. Moral modeling happens when heroes, because they are often symbolic and transcendental in nature, remind others about the good in the world and show what morals or values that are important to a society (Kinsella et al., 2015b).

Together these concepts comprise the Hero Functions Framework, which asserts that society needs heroes because they provide specific functions for society (Kinsella et al., 2015b, 2017). These functions are a product of an individual interacting with a hero, real or fictional, that can be empirically measured to discern to what extent heroes impact others. One concern with these theories is their age, being published within a decade of this paper being written. Therefore, little empiric work has been done to test whether or not common conceptions of heroes is valid in an experimental setting.

\section{Schwartz's Theory of Values}

Schwartz (Schwartz, 2012) found that there were 10 near universal human values, that was later expanded to 19 distinct values that designed meant to do a better job addressing differences across cultures, while still having unique associations with other variables (Schwartz, 2017). Values are the beliefs people hold that motivate behavior or actions. Schwartz's theoretical model arranges values in a quasi-circular structure with similar values being located closer together while contrasting values are located further from each other. These values are separated by the underlying motivations they represent (Schwartz, 2012). This theory has been used across many countries and has provided data that supports the universality of these values (Schwartz, 2012; Lee et al., 2011; Fischer et al., 2010). Although these values seem to stay 
consistent through one's lifetime, the relative importance of these values can shift depending on context. It would be reasonable to assume that exposure to heroes would provide an appropriate context in which the relative importance of one's values would change to align with that hero. These refined values are: self-direction (thought and action), stimulation, hedonism, achievement, power (dominance and resources), face, security (personal and societal), tradition, conformity (rules and interpersonal), humility, universalism (nature, concern, and tolerance), and benevolence (caring and dependability) (Schwartz, 2017). To avoid unnecessary exposition, focus will be shifted toward values that are relevant to heroes. The first value is benevolence, which describes devoting oneself to the welfare of in-group members and being a reliable and trustworthy member of the in-group. Qualities such as helpfulness and honesty overlap nicely with notions of heroes while other qualities like selflessness, altruism, and compassion may also be positively related to heroic schemas. Tradition also overlaps because it is maintaining and preserving cultural, family, and religious traditions, and a quality relating to this value is humility. Achievement also relates to heroes because it has to do with success in terms of social standards and those who value achievement tend to also value intelligence. Other qualities that relate well to heroism and achievement are being talented and powerful. Stimulation, another related value, refers to excitement, novelty, and change. This may be affected by heroes since people who value this characteristic could be considered risk takers or being fearless.

Values typically remain consistent across one's lifetime. However, one method that has been shown to cause a shift in one's values is Value Self-Confrontation (VSC; Rokeach, 1973). This process asks participants to list which values are the most important to them. Participants then receive feedback suggests that their reported values and self-concepts do not align, thus creating a state of self-dissatisfaction. Being in a state of self-dissatisfaction would then motivate 
the participant to change their values to be more consistent with the feedback given to them. VSC has been shown to cause long term changes in values, attitudes, and behaviors (Grube et al, 1994; Schwartz \& Inbar-Saban, 1988) and has been shown to be effective regardless of if the feedback is received anonymously or face-to-face (Rokeach \& Cochrane, 1972). One key component to VSC's effectiveness seems to be the confrontation of one's value priorities and one's ideal self-concept leading to a state of self-dissatisfaction. If participants, after selfevaluating, find that their value priorities align with their ideal self-concept then they will reach a state of self-satisfaction and will not undergo a change in values. But an inconsistency would cause this a state of self-dissatisfaction and lead to change. VSC could explain how the moral modeling function of heroes could cause a shift in one's values. In this way, the values one's personal hero demonstrates would act as the feedback for them to compare their own values against. If a participant finds that their values are inconsistent with their personal hero then they would be more likely to shift their values for better alignment. Since participants are being asked to provide a hero that fits predetermined criteria, it would be expected that any value change would be towards predetermined values such as the ones listed above. Another factor to consider is the level to which one admires the hero that they provide which could affect whether that hero would be considered one's ideal self.

\section{Moral Elevation}

Moral elevation is described as a distinctive feeling of warmth and expansion that is accompanied by admiration for someone who performs a morally beautiful act (Aquino et al., 2011). This is a typical reaction to a moral exemplar or those who function morally at a high level (Walker \& Firmer, 2007). In this case heroes would be considered moral exemplars and their effectiveness to influence others would be affected by the level of inspiration felt by 
witnessing them or their acts. How much one is inspired or admires a hero will affect the degree of which the hero performs their functions. In terms of the actual measure, moral elevation is made up of three components: the emotional component, the desire to be a better person component, and the views of humanity component (Aquino et al., 2011). The emotional component is the feeling of compassion, awe, and admiration. The views of humanity component is the extent to which people adopt a more positive view of humanity after witnessing a morally beautiful act. The desire to be a better person is the final component of measuring moral elevation because one effect of witnessing a morally beautiful act is wanting to employ similar behaviors. Together these components comprise moral elevation which may play a key role as to the effectiveness of heroes to perform their functions.

\section{The Current Study}

\section{Purpose}

While studies in this field concerning the nature and qualities of heroes or heroic actions themselves is comparatively large, the research on how heroes affect those who interact with them is mostly theoretical. This lack of research has caused authors in this field to suggest that more research should be conducted to investigate the specific effects that heroes have in an experimental setting (Kinsella et al., 2015a, 2015b, 2017; Allison \& Goethals 2016; Franco et al., 2011; Sullivan \& Venter 2005). This is an important step in expanding the science of heroism because the interaction between heroes and the individual are what ingrain them into a society, and can illuminate why a society needs heroes, real or fictional. An extensive search of the literature found two studies that have investigated the effects that a hero can have on an individual's behavior and self-concept (Staats et al., 2010; Sullivan \& Venter, 2005) and found 
interesting results but relied on the amount of personal identification with a certain hero or were focused on a specific phenomenon such as academic honesty. This shows not only a lack of research on the direct effects of heroes but that more work needs to be done to evaluate the current theories on what roles heroes play in a culture.

The authors behind the Hero Functions Framework (HFF, Kinsella et al., 2015b) have requested that more research be done to experimentally evaluate their model. This current study will investigate the validity of the moral modeling function of heroes by means of evaluating participants' values after reflecting on empirically valid heroic stimuli. Specifically, participants will engage in an autobiographical memory task, asking them to reflect on a person they know whom fits specific traits people often associate with "heroes" (derived from HFF research). This method of reflection on autobiographical memories serves as a way to access the heroic schema without having a hero actually there. Previous uses of autobiographical memories as a way to investigate short and long-term effects of violent media has produced good results (Harris et al., 2000). Researchers using autobiographical memories were investigating the short-term and longterm effects of watching a scary movie on a date. Participants were asked to recall a time when they watched a scary movie on the date and then were assessed on gender-role traditionality, sensation seeking and dispositional empathy. Results showed different effects due to gender as well as some social utility in seeing a scary movie while on a date with someone of the opposite gender. While heroism and violent media are definitely separate areas of study, enough people witness heroes through various forms of media to a similar degree that they would witness violence. This would suggest that autobiographical memories for violent media and heroic media would not be exceedingly different from one another in terms of theoretical impact on an individual. It would also be reasonable to conclude that experiencing heroism or heroes directly 
and not through any kind of media would leave a more impactful memory that would produce better results.

\section{Hypotheses}

Values. Values are something all people have and they remain relatively consistent across one's life (Schwartz, 2012). However, the expression of certain values over others often depends on the context one is in. For example, one may prioritize the values of tradition or benevolence while in church or worship and prioritize the values of hedonism or stimulation while on vacation. In this line of thought it is not unnecessary to assume that thinking about or reflecting on heroes could create a context in which values related to heroism may express themselves. Due to this, I hypothesize that benevolence, achievement, tradition, and stimulation will be prioritized to a higher degree by those who have reflected on heroes than those who have not (Hypothesis 1).

Moral Elevation. Moral elevation may also play a key role in the relation between heroes and their functions. This is because the extent to which one feels admiration for a hero will affect how much that hero can influence them. This may be the case regarding heroes influencing one's values. Therefore, I hypothesize that moral elevation will mediate the effect of reflecting on heroes and the prioritization of benevolence (Hypothesis 2a), achievement (Hypothesis 2b), tradition (Hypothesis 2c), and stimulation (Hypothesis 2d). 


\section{CHAPTER III: METHODS}

\section{Participants}

Participants were collected using the Department of Psychology's SONA system which allows students registered in an undergraduate psychology class to sign up for a study in exchange for course extra credit.

\section{Procedure}

After signing up, participants then used a link which brought them to the online survey. After confirming their consent, participants provided basic demographic information such as age, gender, and ethnicity. They were then randomly assigned to either reflect on a hero in their life or on an average college student (the independent variable). Participants then had to complete a measure of Moral Elevation and a values measure (the dependent variables). Upon completing these measures, participants completed the survey and were then compensated with extra credit in their undergraduate psychology course.

\section{Hero condition}

The prompt for the hero condition was "Think of someone, real or fictional, who has embodied most or all of the following traits: bravery, moral integrity, courageousness, protecting, conviction, honesty, altruism, self-sacrificing, selflessness, determination, saving, inspiring, and helpful, and explain why they would be considered a hero to you?" The prompt was meant to cause autobiographical reflection that would activate their schemas. The traits listed were used to remain theoretically consistent when evaluating the Hero Functions Framework (Kinsella et al., 2015a). 


\section{College Student condition}

The prompt for the control condition was "Think of someone, real or fictional, who has embodied the most or all of the following traits: agreeable, organized, emotionally stable, extraverted, aggressive, decisiveness, optimism, and driven and explain why they would be considered an average college student to you?" These traits were taken from an article investigating personality traits and life satisfaction amongst college students (Lounsbury et al., 2005). These prompts are meant to produce neutral autobiographical memories in the individual in order to serve as a comparison for a direct experience of heroism.

\section{Dependent measures}

After writing and reflecting on this, participants then completed a measure of moral elevation (Arquino et al., 2011). This was taken to examine the degree to which participants were affected by the manipulation, and to what extent they feel inspired by the activation of their heroic schema. These items are meant to measure the 'emotional', 'views of humanity', and 'desire to be a better person' components that make up moral elevation. These subscales had a Cronbach's alpha of .78, .86, and .90 respectively (Arquino et al., 2011). The items use a 5-point rating scale ( 1 being "not at all or never" and 5 being "very much or always") and include items such as "How much admiration do you feel after reflecting on the hero in your life?" This scale has been used in previous research and adequately measures moral elevation by measuring its three components (Arquino et al., 2011). This study will utilize the entire measure to measure moral elevation.

Participants then completed the Best-Worst Refined Values Scale (BWVr; Lee et al., 2019) which measured the values in Schwartz's refined value theory using Best-Worst scaling (BWS; Lee et al., 2009). Test-retest reliability of this measure showed a correlation of .65, a 
similar correlation reported in other studies using different instruments. The convergent and discriminant validity was evaluated and supported by a multimethod-multitrait analysis of the PVQ-RR and BWVr (Lee et al., 2019). Another benefit of using this measure is that the BWVr has provided data that supports its ability to differentiate between values and to reduce response bias better than its mean centered counterpart.

Best-Worst scaling (BWS) prevents response bias by forcing participants to discriminate between items by choosing the most distinct pairs (Lee et al., 2008). It does so by providing a set of 3-5 items and asks participants to select which is the best option and which is the worst option, leaving the others neutral and by recording the frequency that an item gets selected as best or worst. Participants respond to several combinations of these items which are designed for the equal appearance of each set of items. The result is a distinct ranking of the items that are being measured. This method has been applied to the SVS before, and has shown better distinction between the values, and were more consistent with Schwartz's theoretical structure (Lee et al., 2008). This method of measurement has also been applied to Schwartz's refined theory of 19 values and shown similar results, as well as arguing for an additional value (Lee et al., 2019). This way of measuring values also is easier for participants to complete as well as taking less time (Lee et al., 2008). Overall, this method should be adequate for measuring values after reflecting on heroes, where distinctiveness between values is critical. 


\section{CHAPTER IV: RESULTS}

Three hundred and thirty-six responses were collected. Of those 336 responses, 240 responses were used for analysis. Responses were removed if they failed one or more of the attention checks or did not adequately respond to the prompt as previously stated. Participants' responses to the prompt were removed if the response was blank or if the response did not acknowledge the prompt. Responses were also removed if the duration of the response fell outside of the $5^{\text {th }}$ percentile ( 6 minutes) and the $95^{\text {th }}$ percentile (54 minutes).

Participants' age ranged from 18 -years-old to 49 -years old $(M=19.4, S D=3.1)$. Onehundred and seventy-six participants identified themselves as European-American or White (73.3\%); 18 participants identified themselves as Black (8\%); 22 participants identified themselves as Latino/Latina (9.2\%); 8 participants identified themselves as Biracial or Multiracial (3.3\%); 7 participants identified themselves as Asian-American (7\%); 5 participants identified themselves as being of middle-eastern descent (5\%); 3 participants identified themselves as other (1.3\%); and 1 participant identified themselves as a Pacific Islander (.4\%). One-hundred and ninety-eight participants identified their gender as female (82.5\%), 37 participants identified themselves as male (15.4\%), 3 participants identified themselves as nonbinary $(1.2 \%)$, and 2 participants identified as other $(.01 \%)$.

Analyses were conducted using Statistical Package for Social Sciences version 26 (SPSS) with Hayes’ PROCESS (2017). Mediation models were tested using 10,000 bootstrapped samples to obtain $95 \%$ confidence intervals. For moral elevation, the three subscales' scores were summed to provide an overall score on the total measure. In order to analyze the BWVr, the number of times the value was selected as the worst was subtracted from the number of times it 
was selected as the best option to create the BWS (Best-Worst Score) for each value. The means and standard deviations for each of the outcome variables are listed in Table 1.

\section{Table 1}

Means and Standard Deviations for Moral Elevation, Benevolence, Stimulation, Achievement, and Tradition.

\begin{tabular}{ccccccc}
\hline Condition & $\mathrm{N}$ & $\begin{array}{c}\text { Moral } \\
\text { Elevation }\end{array}$ & Benevolence & Stimulation & Achievement & Tradition \\
\hline Hero & 119 & $60.54(8.12)$ & $4.97(2.82)$ & $.24(1.79)$ & $.55(1.60)$ & $-1.34(2.19)$ \\
$\begin{array}{c}\text { College } \\
\text { Student } \\
\text { Total }\end{array}$ & 121 & $56.02(8.57)$ & $4.74(2.54)$ & $.29(1.72)$ & $.78(1.79)$ & $-.95(2.07)$ \\
& 240 & $58.26(8.63)$ & $4.85(2.68)$ & $.26(1.75)$ & $.66(1.70)$ & $1.14(2.14)$ \\
\hline
\end{tabular}

Mean (Standard Deviation) for benevolence, stimulation, achievement, and tradition, positive values mean the value was selected as best more than it was selected as worse. Negative values mean the values were selected as worse more that it was selected as best.

Hypothesis 1. A multivariate analysis of variance was used to test the effect of condition on moral elevation, benevolence, achievement, tradition, and stimulation. Overall, the effect of experimental condition on the outcome variables was highly significant, Wilks' $\Lambda=.92, F(5$, $234)=4.0, p=.002$, partial eta squared $=.08$. Moral elevation was the driving force behind the significance of this effect (partial eta squared $=.069$ ). This makes sense because condition and moral elevation were also highly significantly correlated as seen in Table 2. Experimental condition did not account for a significant proportion of the variance in any of the hypothesized values (all partial eta squares < .01). This means that reflecting on one's heroes or an average college student had no direct effect on one's values. 


\section{Figure 1}

Standardized Regression coefficients for the relation between condition and benevolence as mediated by moral elevation. Hero condition was coded as one, control condition was coded zero.

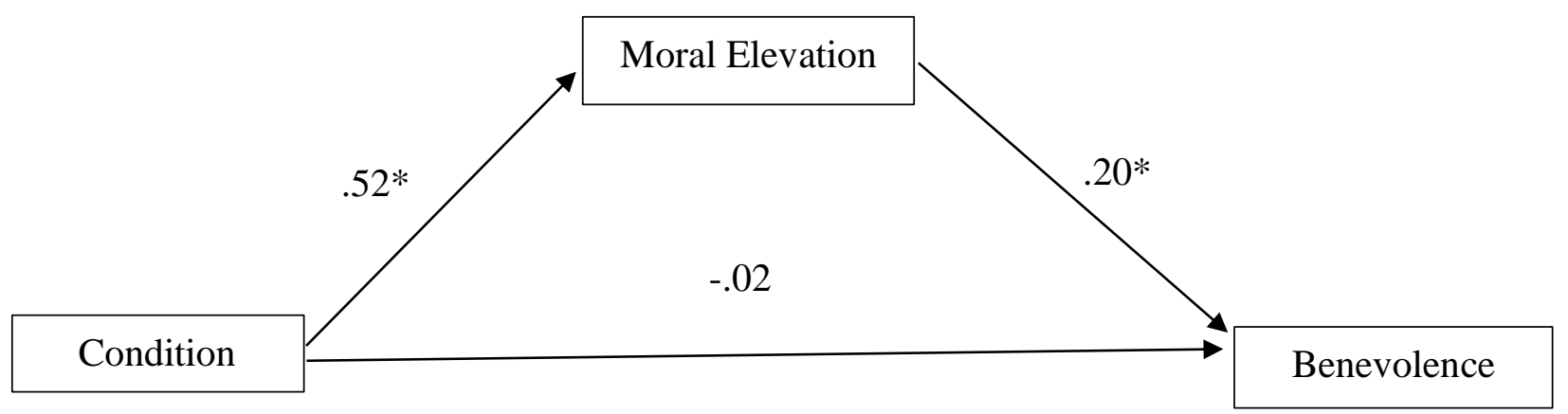

$* p<.01$

Hypothesis 2a. The model explained a significant proportion of the variance in benevolence, $R^{2}=.04, F(2,237)=4.90, p=.008$. As seen in Figure 1 , there was a nonsignificant direct effect, $\beta=-.02, b=-.05, t(238)=-.15, p=.88$. Experimental condition significantly predicted moral elevation, $\beta=.52, b=4.52, t(238)=4.17, p<.001$. Moral elevation significantly predicted higher BWS of benevolence, $\beta=.20, b=.06, t(238)=3.05, p<$ .001 . The results also showed a statistically significant indirect effect from experimental condition to the BWS of benevolence through moral elevation $(\beta=.11,95 \% \mathrm{CI}=[.03, .19])$. 
This means that participants who reflected on heroes reported higher levels of moral elevation and prioritized benevolence more than participants who reflected on college students.

Hypothesis 2b. The model did not explain a significant proportion of the variance in achievement, $R^{2}=.01, F(2,237)=.84, p=.43$. The results showed that the experimental condition had an insignificant direct effect on achievement, $\beta=-.10, b=-.18, t(238)=-.82, p=$ .41. Moral elevation did not have a significant effect on the BWS for achievement, $\beta=-.05, b=-$ $.01, t(238)=-.75, p=.45$. A mediation model was not supported because there was a statistically insignificant indirect effect from experimental condition to the BWS of achievement through moral elevation $(B=-.03,95 \% \mathrm{CI}=[-.10, .03])$. This means that which prompt participants reflected on had no effect on achievement mediated through moral elevation.

Hypothesis 2c. The model did not explain a significant proportion of the variance in tradition, $R^{2}=.01, F(2,237)=1.08, p=.34$. The results showed that there was a non-significant direct effect between experimental condition and the BWS for tradition, $\beta=-.20, b=-.42, t(138)$ $=-1.47, p=.14$. Moral elevation had a non-significant effect on the BWS for tradition, $B=.02, b$ $=.006, t(138)=.34, p=.74$. The results showed a statistically insignificant indirect effect from experimental condition to the BWS of tradition through moral elevation $(\beta=.01,95 \% \mathrm{CI}=[-.05$, .09]). This means that which prompt participants reflected on had no effect on tradition mediated through moral elevation.

Hypothesis 2d. The model did not explain a significant proportion of the variance in stimulation, $R^{2}<.001, F(2,237)=.03, p=.97$. The results showed a non-significant direct effect of experimental condition on the BWS for stimulation, $\beta=-.03, b=-.05, t(238)=-.21, p$ $=.83$. Moral elevation did not have a significant effect on the BWS for stimulation, $\beta=-.004, b$ 
$=-.001, t(238)=-.06, p=.96$. The results showed a statistically insignificant indirect effect

from experimental condition to the BWS of stimulation through moral elevation $(B=-.002,95 \%$

$\mathrm{CI}=[-.08, .06])$. This means that which prompt participants reflected on had no effect on

stimulation mediated through moral elevation.

\section{Table 2}

Correlations for Moral Elevation, Benevolence Stimulation, Achievement, and Tradition.

\begin{tabular}{ccccccc}
\hline Dependent Measures & Condition & $\begin{array}{c}\text { Moral } \\
\text { Elevation }\end{array}$ & Benevolence & Stimulation & Achievement & Tradition \\
\hline Condition & 1.00 & - & 1.00 & - & - & - \\
Moral Elevation & $.26^{* *}$ & $.20^{* *}$ & 1.00 & - & - & - \\
Benevolence & .04 & -.01 & -.09 & 1.00 & - & - \\
Stimulation & -.02 & -.06 & -.08 & $.20^{* *}$ & 1.00 & $.15^{*}$ \\
Achievement & -.07 & -.003 & .12 & .001 & 1.00 \\
Tradition & -.09 & & & & - \\
\hline
\end{tabular}

$* p<.05, * * p<.01$ 


\section{CHAPTER V: DISCUSSION}

The current study examined the experimental validity of HFF by asking participants to reflect on heroes in their lives and completing a measure of personal values and moral elevation. It was hypothesized that those who reflected on heroes would report higher scores of moral elevation and prioritize benevolence, stimulation, achievement, and tradition when compared to those who reflected on college students. The results showed that those who reflected on heroes reported higher levels of moral elevation which was shown to mediate the relation between reflecting on heroes or college student and the prioritization of benevolence.

Reflecting on heroes or college students had little direct effects on one's values. One possible explanation for this is that the hypothesized values were selected using a priori assumptions as to which values corresponded to the characteristics of heroes participants were reflecting on. Testing only the hypothesized values limited the possible findings to those specific values and ignored other values that may have also been prioritized to a greater degree by reflecting on heroes. If heroes model a wide range of values, then testing only four of ten possible values may not be adequate. Another possible explanation is that benevolence and tradition fall opposite of stimulation and achievement on the values circumplex. Therefore, the prioritization of one set of values may have reduced the importance of the other values since they represent opposing motivations (Schwartz, 2017).

One of the biggest findings of the current study is that moral elevation is influence by reflecting on heroes. As seen in Table 2, reflecting on heroes and scores of moral elevation were significantly correlated. While this was not a hypothesized finding, it is important to discuss since it drives the indirect effect of reflecting on heroes and benevolence. This finding is logically coherent because heroes functioning as moral exemplars, those who live their lives with 
moral excellence, would directly affect feelings of awe and inspiration accompanied when one experiences a morally beautiful act. Having participants write and reflect on the heroes in their lives seems to have elicited the same feelings as someone who witnessed an act of moral beauty first-hand. This is important because it confirms that heroes are similar enough to moral exemplars and the actions of those exemplars can inspire those who witness it. This seemed to have played a key role in heroes affecting the value of benevolence.

Though there were no direct effects of the manipulation on the participants' values, the results found that moral elevation mediated the relation between reflecting on heroes and benevolence. This suggests that heroes can inspire feelings of admiration and that these feelings can affect the relative importance of benevolence. Benevolence related to committing oneself to the group and becoming a reliable and dependable group member (Schwartz, 2017). This means that feelings of moral elevation can cause people to prioritize group membership. Benevolence is a value that focuses on others which suggests that those who reflect on heroes are more likely to focus on others around them. This is interesting since heroes could also cause someone to prioritize excitement, courage, or intelligence because these are also characteristics associated with heroes and are theoretically opposite from benevolence. This could explain the lack of effect that heroes had on the other values.

Tradition, stimulation, and achievement were not directly affected by the manipulation or indirectly affected through moral elevation. Due to the effect moral elevation had on benevolence it would make sense that opposing values of achievement and stimulation would show little change as previously discussed. Tradition, however, is puzzling because of its proximity to benevolence on the circumplex. Tradition was selected as a hypothesized value because it relates to humility which is a common characteristic of heroes (Kinsella et al., 2015a). 
Looking at the entire value of tradition shows that it is also related to respect for tradition, detachment, and moderation which is theoretically unrelated to heroism. It seems as though tradition was not theoretically related to heroes for there to be an effect.

\section{Limitations and Future Research}

The current study was the first attempt to apply not only HFF but the BWVr in an experiment. Further, this study was the first to employ a hero schema priming paradigm using the criteria provided by Kinsella et al. (2015). Due to this, there are some natural limitations that need to be addressed in order to further develop this line of experimental research.

Schwartz's theory of personal values was not created with heroes in mind so there may be a disconnect between the values measured by its instruments and the values modeled by heroes. This theory of values and the BWVr were chosen for this experiment due to their strong validity and psychometric properties. Future research should evaluate the moral modeling function with other theories that are more related to heroes or instruments that are more sensitive to measuring the effects of heroes. Another possible limitation is the selection of only four values which could have constrained this theory's ability to measure the values modeled by heroes. Future research should test all of the values measured by the BWVr in an exploratory study or select values similar to benevolence such as universalism.

Another potential limitation was the control group. Having participants reflect on average college students was thought to provide a neutral comparison to the hero condition. However, post hoc analyses showed that those in the control group reported higher self-directed values which are theoretically different from other-focused values such as benevolence. This would suggest that those in the control condition, which was comprised of undergraduate college students, were reflecting on theoretical members of their in-group which could have led them to 
prioritize values related to themselves. This could have acted as a contrast of opposite manipulations instead of a comparison of neutral and manipulated group. But considering that there were only indirect effects on one value, it seems like this contrasting effect was minimal in its impact on the results but should be considered in future research.

This study sampled from a WEIRD population (Western, Educated, Industrialized, Rich, and Democratic; Henrich et al., 2010) and therefore the results found may not generalize to other populations. However, this can be seen as a necessary limitation since the creators of HFF also developed their theory sampling from a WEIRD population and stated this as a limitation. The earliest heroes came about through myths and stories which were formed and influenced by the societies where they were created. Joseph Campbell, one of the first scholarly experts on heroes found that while heroic narratives tend to have a similar structure, the uniqueness of each story was due to its culture of origin (Campbell, 2008). Therefore, heroes and the values they model are contingent on the culture they exist in. Currently, most psychological research has centered on western conceptions of heroes. While there is no work on how culture may change how heroes are defined, future research should sample from non-WEIRD populations to determine the effect culture has on the concept of heroism as well as the generalizability of HFF and other findings in the hero literature.

Due to the similarity between the archetypes of heroes, leaders, and role models, it is possible that participants reflected on a role model or leader instead of a hero. This could affect the results because a hero may model different values than a leader or role model. While these archetypes were found to be theoretically separate from each other there is some overlap between them (Kinsella et al., 2015a). Attempts to reduce this included having participants reflect on traits that were the most closely related to heroes and labeling these traits as heroic. Future 
research should investigate if there are differences in value prioritization depending on which archetype participants reflect on.

The results found in this study can indicative of two things: the first being that heroes typically model values concerning the well-being of others such as self-sacrifice which led values such as benevolence to become more salient when participants were inspired by the heroes in their own lives; the other being that reflecting on the heroes in one's life causes feelings of moral elevation which leads to the prioritization of values that focus on others' wellbeing. The former conclusion could suggest that heroes model values that are more similar to benevolence than other values such as achievement or stimulation. The latter conclusion suggests that reflecting on heroes seems to have activated the enhancing function to a greater degree than the moral modeling function. Due to the lack of direct effects in this experiment, it seems more likely that the latter conclusion is more likely. Regardless, future research should seek to test the experimental validity of the enhancing and protecting functions as well as evaluate the interdependence between the three functions.

\section{Conclusion}

This study applied constructs from the heroism literature in order to test if the moral modeling function changed one's values and if moral elevation played a mediating role in that relation. This was tested by asking participants reflect on heroes or college students and comparing their scores on measures of moral elevation and personal values. Moral elevation was found to be strongly related to reflecting on heroes. Benevolence was indirectly affected by reflecting on heroes through moral elevation. While the null findings suggest further refinement of this design, the significant findings confirm that heroes impact values by elevating people to value their relationships with others. 


\section{REFERENCES}

Allison, S. T., Goethals, G. R., \& Kramer, R. M. (2017). Handbook of Heroism and Heroic Leadership (S. T. Allison, G. R. Goethals, \& R. M. Kramer (Eds.)). Routledge/Taylor \& Francis Group.

Allison, S. T., \& Goethals, G. R. (2016). Hero worship: The elevation of the human spirit. Journal for the Theory of Social Behaviour, 46(2), 187-210. https://doiorg.libproxy.lib.ilstu.edu/10.1111/jtsb.12094

Aquino, K., McFerran, B., \& Laven, M. (2011). Moral identity and the experience of moral elevation in response to acts of uncommon goodness. Journal of Personality and Social Psychology, 100(4), 703-718. https://doi-org.libproxy.lib.ilstu.edu/10.1037/a0022540

Becker, S. W., \& Eagly, A. H. (2004). The Heroism of Women and Men. American Psychologist, 59(3), 163-178. https://doi-org.libproxy.lib.ilstu.edu/10.1037/0003066X.59.3.163

Campbell, J. (2008). The hero with a thousand faces (Vol. 17). New World Library.

Chrzan, K., \& Peitz, M. (2019). Best-Worst Scaling with many items. Journal of Choice Modelling, 30, 61-72.

Fischer, R., Vauclair, C.-M., Fontaine, J. R. J., \& Schwartz, S. H. (2010). Are individual-level and country-level value structures different? Testing Hofstede's legacy with the Schwartz Value Survey. Journal of Cross-Cultural Psychology, 41(2), 135-151. https://doiorg.libproxy.lib.ilstu.edu/10.1177/0022022109354377 
Franco, Z. E., Allison, S. T., Kinsella, E. L., Kohen, A., Langdon, M., \& Zimbardo, P. G. (2018). Heroism research: A review of theories, methods, challenges, and trends. Journal of Humanistic Psychology, 58(4), 382-396. https://doiorg.libproxy.lib.ilstu.edu/10.1177/0022167816681232

Franco, Z. E., Blau, K., \& Zimbardo, P. G. (2011). Heroism: A conceptual analysis and differentiation between heroic action and altruism. Review of General Psychology, 15(2), 99-113.

Goethals, G. R., \& Allison, S. T. (2012). Making heroes: The construction of courage, competence, and virtue. In Advances in Experimental Social Psychology (Vol. 46, pp. 183-235). Academic Press.

Grube, J. W., Mayton, D. M., \& Ball-Rokeach, S. J. (1994). Inducing change in values, attitudes, and behaviors: Belief system theory and the method of value self-confrontation. Journal of Social Issues, 50(4), 153-173.

Harris, R. J., Hoekstra, S. J., Scott, C. L., Sanborn, F. W., Karafa, J. A., \& Brandenburg, J. D. (2000). Young men's and women's different autobiographical memories of the experience of seeing frightening movies on a date. Media Psychology, 2(3), 245-268. https://doi-org.libproxy.lib.ilstu.edu/10.1207/S1532785XMEP0203_3

Hayes, A. F. (2017). Introduction to mediation, moderation, and conditional process analysis: A regression-based approach. Guilford publications.

Henrich, J., Heine, S. J., \& Norenzayan, A. (2010). The weirdest people in the world?. Behavioral and Brain Sciences, 33(2-3), 61-83. 
Kinsella, E. L., Ritchie, T. D., \& Igou, E. R. (2017). Attributes and applications of heroes: A brief history of lay and academic perspectives. In S. T. Allison, G. R. Goethals, \& R. M. Kramer (Eds.), Handbook of Heroism and Heroic Leadership. (pp. 19-35).

Routledge/Taylor \& Francis Group.

Kinsella, E. L., Ritchie, T. D., \& Igou, E. R. (2015). Zeroing in on heroes: A prototype analysis of hero features. Journal of Personality and Social Psychology, 108(1), 114-127. https://doi-org.libproxy.lib.ilstu.edu/10.1037/a0038463

Kinsella, E. L., Ritchie, T. D., \& Igou, E. R. (2015). Lay perspectives on the social and psychological functions of heroes. Frontiers in Psychology, 6.

Kohen, A., Langdon, M., \& Riches, B. R. (2019). The making of a hero: cultivating empathy, altruism, and heroic imagination. Journal of Humanistic Psychology, 59(4), 617-633.

Lee, J. A., Sneddon, J. N., Daly, T. M., Schwartz, S. H., Soutar, G. N., \& Louviere, J. J. (2019). Testing and extending Schwartz refined value theory using a Best-Worst scaling approach. Assessment, 26(2), 166-180. https://doiorg.libproxy.lib.ilstu.edu/10.1177/1073191116683799

Lee, J. A., Soutar, G. N., Daly, T. M., \& Louviere, J. J. (2011). Schwartz values clusters in the United States and China. Journal of Cross-Cultural Psychology, 42(2), 234-252. https://doi-org.libproxy.lib.ilstu.edu/10.1177/0022022110396867

Lee, J. A., Soutar, G., \& Louviere, J. (2008). The best-worst scaling approach: An alternative to Schwartz’s Values Survey. Journal of Personality Assessment, 90(4), 335-347. https://doi-org.libproxy.lib.ilstu.edu/10.1080/00223890802107925 
Lounsbury, J. W., Saudargas, R. A., Gibson, L. W., \& Leong, F. T. (2005). An investigation of broad and narrow personality traits in relation to general and domain-specific life satisfaction of college students. Research in Higher Education, 46(6), 707-729.

Matsuba, M. K., \& Walker, L. J. (2005). Young Adult Moral Exemplars: The Making of Self Through Stories. Journal of Research on Adolescence, 15(3), 275-297. https://doiorg.libproxy.lib.ilstu.edu/10.1111/j.1532-7795.2005.00097.x

Paulhus, D. L. (1991). Measurement and control of response bias. In J. P. Robinson, P. R. Shaver, \& L. S. Wrightsman (Eds.), Measures of Personality and Social psychological Attitudes. (pp. 17-59). Academic Press. https://doiorg.libproxy.lib.ilstu.edu/10.1016/B978-0-12-590241-0.50006-X

Rokeach, M., \& Cochkane, R. (1972). Self-Confrontation and Confrontation With Another as Determinants of Long-Term Value Change. Journal of Applied Social Psychology, 2(4), 283-292.

Schwartz, S. H. (2017). The refined theory of basic values. In S. Roccas \& L. Sagiv (Eds.), Values and behavior: Taking a cross cultural perspective. (pp. 51-72). Springer International Publishing. https://doi-org.libproxy.lib.ilstu.edu/10.1007/978-3-319-56352$7 \_3$

Schwartz, S. H. (2012). An Overview of the Schwartz Theory of Basic Values. Online Readings in Psychology and Culture, 2(1). http://dx.doi.org/10.9707/2307-0919.1116

Schwartz, S. H., \& Inbar-Saban, N. (1988). Value self-confrontation as a method to aid in weight loss. Journal of Personality and Social Psychology, 54(3), 396. 
Staats, S., Hupp, J. M., \& Hagley, A. M. (2008). Honesty and heroes: A positive psychology view of heroism and academic honesty. The Journal of Psychology: Interdisciplinary and Applied, 142(4), 357-372. https://doi-org.libproxy.lib.ilstu.edu/10.3200/JRLP.142.4.357372

Sullivan, M. P., \& Venter, A. (2010). Defining heroes through deductive and inductive investigations. The Journal of Social Psychology, 150(5), 471-484. https://doiorg.libproxy.lib.ilstu.edu/10.1080/00224540903366602

Sullivan, M. P., \& Venter, A. (2005). The Hero Within: Inclusion of Heroes into the Self. Self and Identity, 4(2), 101-111. https://doiorg.libproxy.lib.ilstu.edu/10.1080/13576500444000191

Summerville, A., \& Roese, N. J. (2008). Self-report measures of individual differences in regulatory focus: A cautionary note. Journal of Research in Personality, 42(1), 247-254. https://doi-org.libproxy.lib.ilstu.edu/10.1016/j.jrp.2007.05.005

Walker, L. J., Frimer, J. A., \& Dunlop, W. L. (2010). Varieties of moral personality: Beyond the banality of heroism. Journal of Personality, 78(3), 907-942. https://doiorg.libproxy.lib.ilstu.edu/10.1111/j.1467-6494.2010.00637.x

Walker, L. J., \& Frimer, J. A. (2007). Moral personality of brave and caring exemplars. Journal of Personality and Social Psychology, 93(5), 845. 